\title{
Quadrinhos como método de divulgação da cultura popular brasileira: um estudo de caso na escola Erc E F Centro Social Auxilium.
}

Comics as a method to spread Brazilian popular culture: a case study at the school Erc E F Social Center Auxilium.

PAMPLONA, Marcele; Especialista; Faculdade Estácio de Sá - Polo IESAM, Belém

marcele.p@hotmail.com

\section{Resumo}

Este artigo tem como objetivo investigar, através da análise de dados feita a partir de um estudo de caso realizado em uma escola Estadual pública de Belém do Pará, se é possível utilizar as histórias em quadrinhos como método de propagação da cultura popular brasileira. O design gráfico toma parte como ferramenta essencial de transformação de signos e imagens em material visual atrativo para a divulgação cultural. Através da utilização de conceitos metodológicos que se baseiam na dinâmica entre a teoria e a prática, obteve-se como resultado da pesquisa a certeza de que histórias em quadrinhos são um meio eficaz de divulgação de cultura.

Palavras Chave: Lendas brasileiras, histórias em quadrinhos, design gráfico.

\section{Abstract}

This article aims to investigate, through the analysis of data made from a case study conducted at a public state school in Belém do Pará, if it is possible to use comics as a method of propagation of Brazilian popular culture. Graphic design takes part as an essential tool for transforming signs and images into attractive visual material for cultural dissemination. Using methodological concepts that are based on the dynamics between theory and practice, the results of the research confirm that comics are an effective means of disseminating culture.

Keywords: Brazilian tales, comics, graphic design. 


\section{Introdução}

A história das histórias em quadrinhos (HQs) é marcada por diversas mudanças e transformações. Apesar de iniciar como entretenimento infantil, os quadrinhos se transformaram com o passar dos anos em uma mídia comunicacional capaz de transmitir diversos tipos de conteúdo. Todavia, mesmo que atualmente as HQs possuam um caráter mais filosófico, muitas pessoas ainda rejeitam essa mídia por acreditarem que seja voltada apenas para o entretenimento.

Pretende-se avaliar se é possível absorver mais aspectos culturais através de textos ou quadrinhos relacionados ao tema. Para isso, foi feito um estudo de caso com alunos da escola pública estadual Erc E F Centro Social Auxilium localizado no bairro da Pedreira, Belém-PA.

O estudo tem como obrigação saber se os quadrinhos são um método mais eficaz de divulgação da cultura do que a que é feita através de conteúdo semântico; livros e textos.

\subsection{Justificativa}

A divulgação dos personagens da cultura popular brasileira de forma educativa e atraente para o contexto popular é um dos motivos que impulsionaram a escolha da temática. Além de valorizar a interculturalidade como forma de reconhecimento e, acima de tudo, o respeito às diferentes caraterísticas étnico-sociais para promover a assimilação dos povos procedentes. Na tentativa de encontrar um meio popular para provocar o interesse das novas gerações no conhecimento popular nacional, se faz necessário uma análise da possibilidade das histórias em quadrinhos se constituírem uma mídia efetiva para a valorização da cultura brasileira.

A produção de uma história em quadrinhos de terror inspirada nas lendas populares brasileiras foi apresentada previamente no trabalho de conclusão de curso (TCC). Onde, após a aplicação de uma pesquisa quantitativa feita com 74 pessoas de várias partes do Brasil, das quais 44 eram leitores frequentes de HQs e 30 não eram, percebeu-se que a maioria dos entrevistados possui mais interesse nas lendas nacionais do que nas europeias, porém, possivelmente devido ao fato dos contos europeus serem mais divulgados nas mídias de comunicação, essas pessoas sabiam mais do folclore de outros países do que do nativo.

Como a interculturalidade é importante na atual conjectura da globalização, encontrar um meio de tornar a cultura nacional conhecida em uma sociedade que cultua o que vem de fora, se torna relevante por tornar possível uma nova abordagem ao tema. Por haver um interesse pessoal no contexto de histórias em quadrinhos e sabendo que esse meio de comunicação pode ser utilizado com diversas finalidades, como, por exemplo, divulgação histórica, filosófica e científica, há o empenho em demonstrar no meio acadêmico que através das HQs é possível popularizar conteúdos de toda uma cultura.

\subsection{Objetivos}

\subsubsection{Objetivo Geral}

Investigar a viabilidade das histórias em quadrinhos como forma de divulgação da cultura através da lenda da Matinta-Pereira.

\subsubsection{Objetivo Específico}

- Descrever o que é história em quadrinhos.

- Relacionar história em quadrinhos e design gráfico. 
- Conceituar o que é cultura e lenda.

- Realizar um estudo de caso com os alunos da turma de Fundamental II.

Analisar os resultados.

\subsection{Procedimentos Metodológicos}

A abordagem da pesquisa será a crítico-dialético que segundo Matins (2002) baseia-se na dinâmica entre o conhecimento e a ação, a teoria e a prática, ou seja, o projeto se propõe analisar o conteúdo cultural dentro de histórias em quadrinhos e saber se esse conhecimento está sendo absorvido pelos leitores. Também haverá uma análise sobre como a falta da difusão da cultural nacional como, por exemplo, as lendas populares brasileiras, afeta o contexto intercultural.

A pesquisa se classifica como explicativa, que segundo Gil (1999) consiste em identificar os fatores que contribuem para a ocorrência de um fenômeno, dessa forma, busca-se desvendar como evitar o esquecimento das lendas brasileiras através da divulgação dos mesmos em histórias em quadrinhos.

Quantos aos procedimentos, a estratégia adotada será o levantamento bibliográfico, que para o ibid significa uma pesquisa em um material já elaborado - constituído de livros e artigos científicos. Os instrumentos utilizados serão livros, TCCs e artigos sobre a temática do projeto, além de pesquisas em sites e informações relativas ao tema. Além de uma pesquisa quanli-quanti para descobrir qual o grau de absorção de conhecimento que as novas gerações têm ao lerem histórias em quadrinhos com conteúdo cultural.

\section{Aporte Teórico}

\subsection{Conceito De Historias Em Quadrinhos ( $\mathrm{Hq})$}

Para Eisner (s/d) apud Mcloud (1995), as histórias em quadrinhos são artes sequenciais onde cada imagem faz parte de uma sequência, mesmo que seja só de dois quadros. A forma artística pode conter várias ideias e imagens, cujo conteúdo é definido pelos criadores.

O nome "arte sequencial visual" também pode ser utilizado para as animações - afinal o filme animado se trata de ilustrações sobrepostas. A diferença para os quadrinhos é que a animação é uma sucessão de quadros temporais e o quadrinho é estático. De modo técnico, histórias em quadrinhos são imagens pictóricas e outras justapostas em sequencias deliberada, destinadas a transmitir informações e/ou a produzir uma resposta no espectador (MCLOUD, 1995).

Tendo em mente a definição técnica de quadrinhos, interpreta-se que é possível afirmar que um manuscrito em imagens pré-colombiano encontrado por cortês em 1519 pode ser considerado uma história em quadrinhos, pois é uma tela ilustrada em série que fala sobre o herói militar e político "garra de tigre", como mostra a figura 01. 
Figura 01: Ilustração de um manuscrito pré-colombiano.

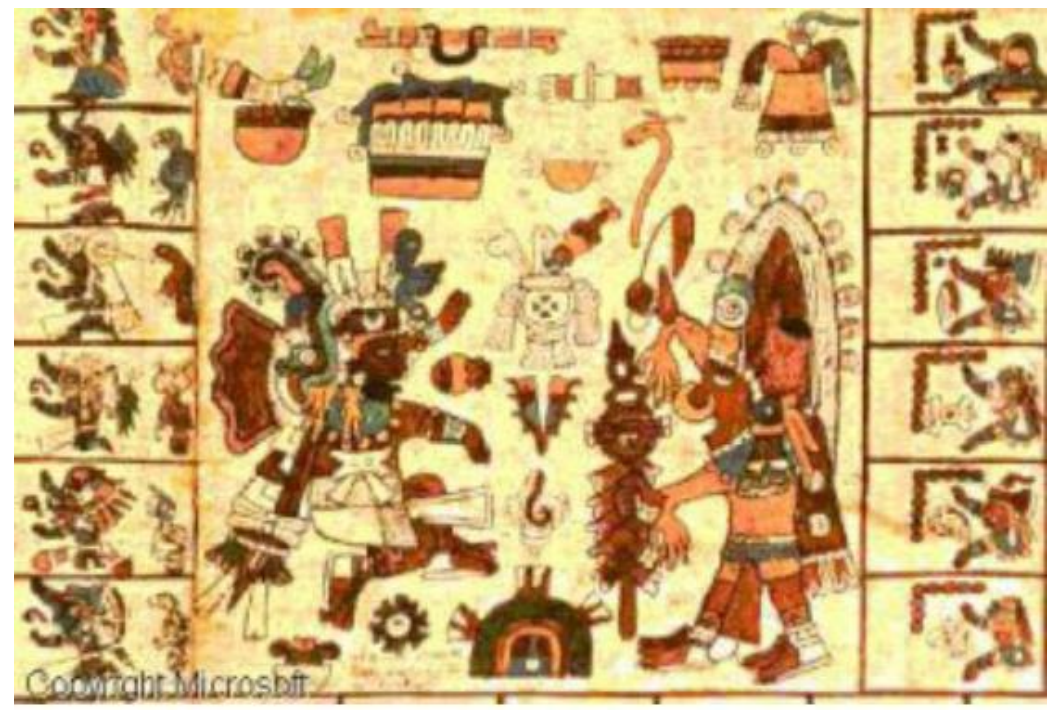

Fonte: Pré-colombiano, 1519.

Segundo Mcloud (1995), as pinturas egípcias são as que mais se assimilam às graphic novels americanas, mesmo considerando que o fluxo das pinturas seja em ziguezague, só de baixo para cima. Apesar dos trabalhos em tapeçaria, vasos e até mesmo desenhos em paredes de cavernas apresentarem uma semelhança com as histórias em quadrinhos que se conhece atualmente, é difícil estipular uma data para definir a verdadeira origem dos quadrinhos.

O que se pode definir são os marcos das histórias em quadrinhos e o primeiro deles foi a criação da imprensa. Com ela, as formas de arte se tornaram populares não apenas para os ricos e poderosos como era anteriormente, mas para todas as classes.

Atualmente os quadrinhos vêm sendo utilizado como uma excelente ferramenta de comunicação. Porém, muitas pessoas ainda não as definem como quadrinhos, mas como ilustrações ou diagramações. Um exemplo disso são os folhetos informativos que existem nos aviões, onde a maioria utiliza apenas desenhos para demonstrar procedimentos de segurança na cabine do avião.

Esse preconceito com o termo quadrinho é antigo, mas ainda reflete o contexto atual e a prova disso é que muitos artistas preferem ser chamados de ilustradores ou artistas comerciais, mesmo com a existência dos termos cartunistas e quadrinistas.

Em algumas ocasiões existe a confusão do termo história em quadrinhos. Muitas vezes um único quadro, como ilustrado na figura 02, é chamado de quadrinho, mas, neste caso, seguindo o conceito de Mcloud (1995), se não há sequência, não pode ser considerado quadrinhos. 
Figura 2: Exemplo de confusão com o termo quadrinhos.

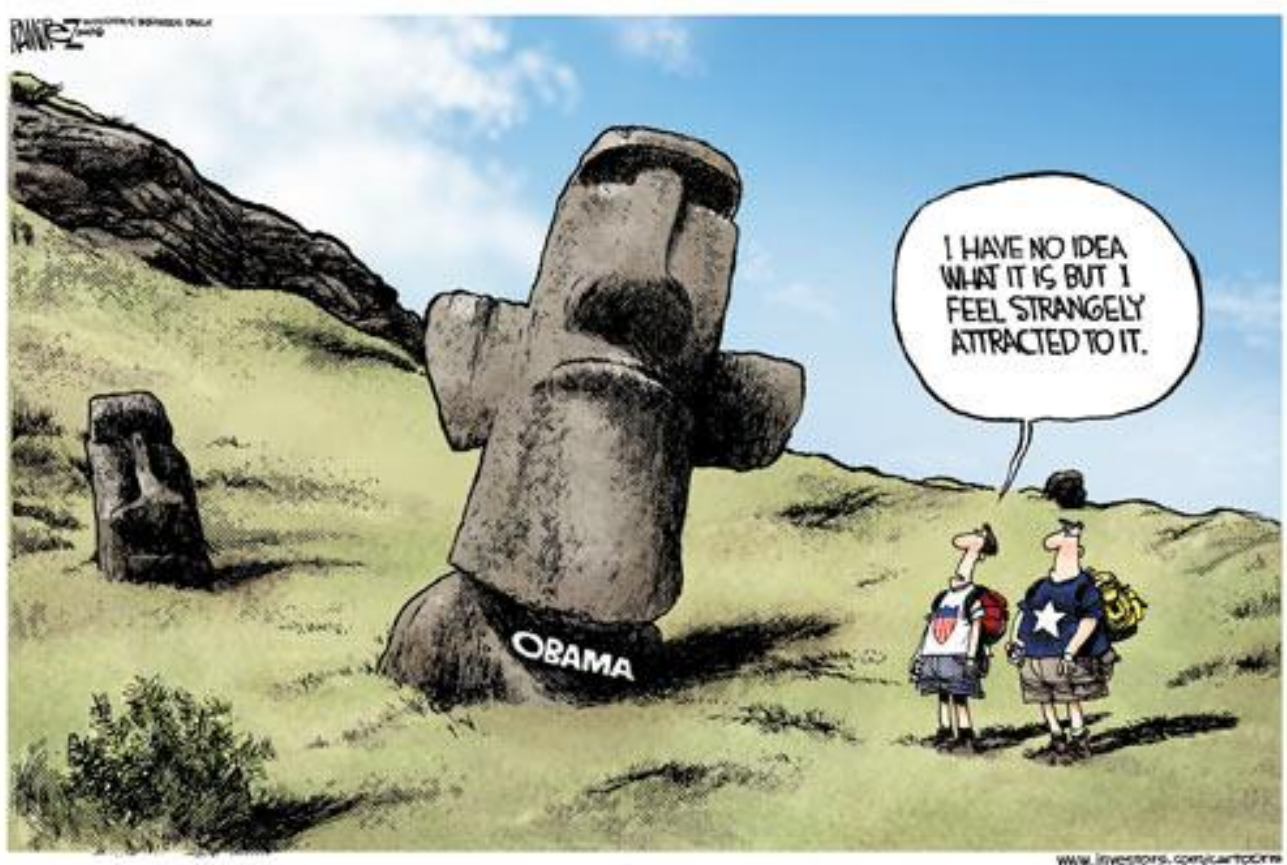

Fonte: Michael Rodriguez, 2008.

Por isso, para evitar confusões neste trabalho, deve-se entender o conceito de história em quadrinhos como uma sequência de quadros que proporcione algum tipo de comunicação, passando uma ideia, mesmo que não utilize palavras para explicar o seu contexto.

\subsubsection{Quadrinhos como Linguagem Comunicacional}

Em 2015 foi publicado um pós-doutorado chamado Unflatening sobre a história em quadrinhos como linguagem comunicacional. Sousanis (2015) estabelece uma relação entre imagem e texto, o autor utilizou de metalinguagem para defender a sua tese. Sua publicação tem a intenção de mudar a compreensão dos leitores para além do que ele considera pensamento bidimensional.

Para Sousani (2015), a maioria das pessoas percebe o mundo em uma única perspectiva e, por isso, elas acabam sendo ludibriadas por entenderem o mundo através de uma única dimensão. Que, devido ao avanço da civilização e até mesmo da ciência, a humanidade se fragmentou criando fronteiras e limites que sufocaram a comunicação e fizeram com que cada sociedade procurasse modos diferentes de entender os mesmos assuntos.

A fixação em um único ponto de vista pode ser uma armadilha, pois o indivíduo acaba procurando apenas o que quer. É necessário outro tipo de abordagem para revelar que uma única verdade é falsa independente dos fundamentos. Ainda segundo ibid, expandir os conhecimentos requer divergência de pensamentos e diversidade de pensadores, ver através dos olhos de outra pessoa (de seu posicionamento e sua visão) torna as pessoas capazes de mudar a visão de unidimensional para multidimensional. 
Então nem tudo aqui é verde? "perguntou Dorothy. As coisas aqui são tão verdes quanto em qualquer outra cidade," - respondeu Oz. - Entretanto, quando você usa óculos de lentes verdes, é claro que tudo para o que olha se torna verde. (BAUM, 1939 apud 14 SOUSANIS, 2015, p.36).

A linguagem não é o único meio para o entendimento, mas é a ferramenta mais utilizada. As palavras têm sido privilegiadas quando é necessário explicar um raciocínio, já as imagens são tradicionalmente consideradas do domínio da estética. Essa segregação acontece devido às imagens serem consideradas ilusórias. Segundo Murdoch (1977) apud Sousanis (2015, p.54), "o objeto que parece dobrar quando entra na água provoca uma perplexidade sobre o que é real".

Figura 03: Ilusão de ótica.

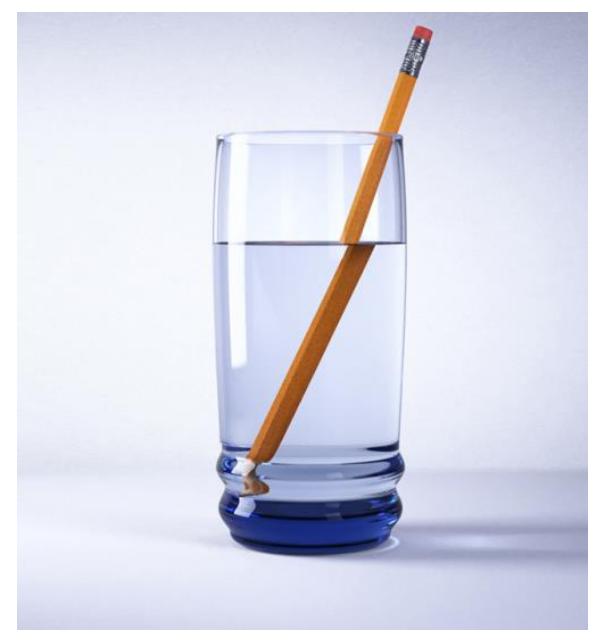

Fonte: M5 Agência Digital, s/d.

Para Platão (s/d) apud Sousanis $(2015$, p.54) existe uma desconfiança na escrita por considerá-la um substituto inferior para a memória, ele tolerava a escrita por considerar que era um mal necessário para expressar os pensamentos. Se o ser humano pode ser iludido por imagens o mesmo pode acontecer com as palavras, pois a descrição de uma imagem na verdade nunca representara a imagem em si - a descrição é uma representação do pensamento de ter visto uma imagem.

As palavras se apresentam em sequência, uma de cada vez como as contas de um rosário, entretanto as imagens podem apresentar tudo de forma simultânea. Ao utilizar um texto como forma primária de assimilação, o que fica de fora da estrutura linear é perdida, por isso a importância de também se empregar figuras para promover expressão visual onde as palavras falharem (IBID).

Como já mencionado, nos quadrinhos o texto é lido de modo sequencial, mas a composição da página também é vista como um todo. A organização das imagens funciona como em uma teia onde cada elemento se torna um com o todo. O significado do conteúdo se enriquece através da interação entre o lado esquerdo do cérebro (direcionado à linguagem) e o lado direito (direcionado à arte).

Ter a perspectiva de que quadrinhos possuem apenas uma dimensão (a de entretenimento visual) é perder a perspectiva dos pontos de vista, é ter uma noção unidimensional de um todo. Muitos quadrinhos fazem questionamentos importantes até sobre fatos históricos, como, por 
exemplo, o Watchmen, que usa heróis como pano de fundo para discutir como seria o modelo de sonho americano caso os EUA tivessem ganhado a guerra do Vietnã. Ou o quadrinho, $V$ de Vingança, que expõe os crimes de um governo totalitário e demonstra que, na realidade, todo poder está nas mãos do povo.

As experiências e interações proporcionadas pelos quadrinhos podem gerar novo conhecimento para modificar a atual perspectiva das pessoas, criando um novo ponto de vista que se torna cíclico à medida que a pessoa procura mais informações desse meio. É apenas necessário que as pessoas modifiquem o preconceito existente em relação aos quadrinhos e entendam que eles também são um meio de comunicação.

\title{
2.2 A Relação Do Design Gráfico Com A Criação De Histórias Em Quadrinho
}

"O designer gráfico é alguém que pode transformar o mundo e o que nele acontece em signos e imagens, que pode fazer visível o invisível" (AICHER, s/d apud FUENTES, 2006). O contexto de atuação do designer gráfico é muito amplo e pode englobar tanto o ambiente físico quanto o emocional, transformando-se em um fator de materialização da comunicação.

Segundo Fuentes (2006), o excesso de imagens visuais torna mais difícil assegurar que a veiculação de uma mensagem em uma mídia irá garantir que esta chegará a seu destinatário.

\begin{abstract}
Cada marca que o designer faz modifica o mundo de alguma forma. Pode fazer com que a comunicação funcione melhor ou pior. Isto não depende de fatores aleatórios; depende, sem dúvida, do designer, que tanto com orgulho como com humildade profissional entende seu papel claramente; depende do estudante de design desenvolver ao máximo suas habilidades intelectuais e técnicas; e depende também do público em geral e de sua transformação em usuários mais críticos, mais informados e mais exigentes. (KNEEBONE, s/d apud FUENTES, 2006).
\end{abstract}

Ibid descreve que, na prática, a metodologia de design gráfico envolve seis etapas: identificação, análise da necessidade, pesquisa, concepção, concretização, controle, avaliação e critica.

A identificação é o ponto de partida de todo processo de design gráfico, consiste na análise do produto exaustivamente - características de consumo, estratégia de vendas, preço dos concorrentes, pontos de vendas e etc. É preciso ter um diagnóstico do produto para saber que necessidades ele irá suprir, quais as razões desencadeadoras desse processo e quais as expectativas em cima do resultado final. (FUENTE, 2006; RIBEIRO, 2008).

O processo de identificação começa levando em conta as expectativas do cliente, tentando discernir quais podem realmente ser aplicadas e quais tem de ser descartadas. Essa etapa é importante para estabelecer a relação de cliente/designer em um plano formal de negócios, especificando horários e forma de pagamento e prazos de entrega.

Ainda na identificação, são determinados os motivos explícitos e implícitos da necessidade do cliente para a definição do projeto - entendendo qual o problema de comunicação do cliente ou da empresa. A partir disso, múltiplas possibilidades de solução do problema aparecerão e cabe ao designer decidir qual solução é a mais adequada para resolver a questão.

A etapa de análise da necessidade se caracteriza pela definição com clareza do projeto após a coleta de dados relacionados direta ou indiretamente ao objetivo que se pretende atingir. As informações adquiridas provêm de várias fontes como o cliente, o ambiente e o contexto cultural, 
por exemplo.

É importante saber quais ações anteriores foram feitas na área da comunicação - quais caminhos de mídia, aspectos culturais e elementos conceituais e estéticos foram utilizados previamente. O próximo passo é estabelecer pautas de marketing que servem para definir os objetivos da comunicação: o público alvo e o resultado que se deseja alcançar. Definindo se o projeto será institucional, enraizado na identidade corporativa da empresa, ou de persuasão, consolidado no âmbito emocional com base em valores intangíveis (FUENTES, 2006).

Após a etapa de análise, considerada elemento de base, o processo será concluído através da pesquisa sobre a concorrência local, a coleta de dados históricos e referências internacionais.

As informações coletadas sobre a concorrência local são relacionadas à maneira como atuam e os elementos que pertencem à mensagem deles. Os elementos culturais próprios se referem à história do cliente ou da empresa - as origens, etnia e cultura.

"A globalização atinge tamanho grau de penetração que a maioria das ideias ou elaborações de design nasce necessariamente dentro de algum parâmetro referencial externo" (FUENTES, 2006. p. 40). Ou seja, a cultura visual se encontra em um estágio de desenvolvimento tão grande que dificilmente se estará trabalhando em um projeto original. Por isso, é necessário um estudo sobre as referências internacionais para que não aconteçam futuros problemas de propriedade intelectual.

A parte de síntese consiste na ordenação do conteúdo adquirido nas etapas anteriores. É o momento de início de tomada de decisões, onde surgirão algumas ideias acerca do que pode ser feito, de recolher os detalhes dentre toda informação adquirida e adicionar a experiência e o trabalho do designer.

Segundo Panizza (2004), o processo criativo não acontece subitamente por fruto do acaso, este só é atingido através de um enorme esforço mental por parte daqueles que pretendem realizar um trabalho criativo.

A criatividade é parte da concepção que o designer tem que fazer a relação à maneira e os elementos que serão utilizados no projeto, decidindo com que intensidade esses elementos formais irão aparecer: forma, cores e signos. Além de determinar acerca do esquema de cores, possíveis tipografias e esquemas gráficos.

Após a preparação de todo processo de base para a realização do projeto, é o momento de concretização do que foi decidido. Porém a materialização do que foi imaginado está condicionado por bordas de encadernação, processos de impressão e acabamentos gráficos.

A complexidade da estrutura, da escala, da tipografia, das cores e das imagens reflete na qualidade do resultado final. É conveniente lembrar que a divulgação do trabalho do designer gráfico, seja um livro único ou uma coleção, de uma revista, de um logotipo ou de um programa de identidade corporativa ou de qualquer dos variados produtos nos quais o trabalho do designer pode desenvolver-se, na maioria das vezes, é divulgado através da reprodução. Por isso os fatores ligados ao material fazem parte do fator comunicativo e, em algumas ocasiões, este se torna o próprio fator se a intervenção gráfica for mínima ou rotineira.

As condições de conhecimento de material muitas vezes só são adquiridas através do conhecimento empírico, por vezes testes e ensaios não correspondem à realidade. Fatores a 
princípio desconsiderados como umidade do ar, temperatura e luz podem alterar o resultado final, por isso é importante o acompanhamento do projeto na gráfica, caso sejam necessários ajustes.

A pré-impressão e impressão são parte da finalização e é o momento do designer "operar" todo o processo. Estar atento a detalhes que passaram despercebidos anteriormente como, por exemplo, a sangria, dimensões, linhas de corte, qualidade, adaptabilidade de fotos e ilustrações, paleta de cores e fontes tipográficas. "[...] nunca devemos esquecer que os erros são como um bumerangue, que inevitavelmente voltam para quem o lançou" (FUENTES, 2006. p. 92).

O acabamento geral é a última etapa de produção e dá a forma final e definitiva ao design. Por se trata de um processo que pode identificar problemas que não são visíveis na tela do computador, essa etapa é necessária para evitar inconvenientes incontornáveis no resultado final.

De acordo com Ribeiro (2008), é nesta etapa que ocorre a finalização dos desdobramentos gráficos e a adaptação para outras mídias, caso seja requisitado.

Em relação ao controle do processo virtual, o acompanhamento também deve ser rigoroso, apesar dos parâmetros serem outros. É fundamental que exista uma coerência na paleta de cores independentemente da plataforma tecnológica de visualização.

O controle de todo processo é crucial para garantir a qualidade do processo de design gráfico, pois é necessário fazer o possível para conseguir o resultado desejado. "Nunca devemos esquecer o fator humano, nem diante de nossa tela, quando realizamos o trabalho, nem 'ao pé da máquina', no momento de exigir qualidade nos resultados finais" (FUENTES, 2006. p. 103).

Ainda segundo ibid, o maior reconhecimento que um designer pode ter é saber que o projeto cumpriu com o seu objetivo, que comunicou o que precisava. Também pode acontecer o fracasso no projeto e isso faz parte do sistema de aprendizado.

Por isso é valoroso a visualização crítica para adquirir conhecimento através dos acertos e dos erros. Todo designer deve ser capaz de ver criticamente o seu próprio trabalho, a fim de que, caso haja algum erro na arte final, seja corrigido antes de seguir a cadeia de produção. Portanto, vale ressaltar que a análise crítica do processo serve de apoio para o crescimento profissional.

Para o desenvolvimento do projeto gráfico da história em quadrinho, o conhecimento destas metodologias se faz fundamental para que, num momento posterior, seja possível a adaptação e a adequação das etapas para a execução do projeto.

Como dito anteriormente, o processo de concepção de uma HQ pode contemplar aspectos relacionados tanto ao design gráfico, quanto ao design de livro e design editorial.

Nesse sentido, o design de livros e o design editorial também é essencial para publicações, pois tratam da estrutura e representam o planejamento do suporte interno (a estrutura é que torna o projeto gráfico reconhecível aos leitores habituais).

\subsection{Analise Intercultural, Folclore E Cultura Popular Brasileira.}

O Brasil, por possuir uma cultura diversificada, tem costumes específicos cultivados em cada região do país. Seja na maneira de falar, no artesanato ou na culinária. É possível perceber, mesmo sendo diferente em cada Estado, a mistura da cultura europeia, indígena e negra que representa a identidade do Brasileiro (DINO, 2006).

Por se tratar de um estudo que utilizou seres míticos da cultura popular brasileira, faz-se 
necessário explicar o termo "cultura popular" para situar em que sentido esses personagens são parte do conhecimento nacional e qual o grau de importância deles.

Segundo Bosi (1922) apud Dino (2006) "cultura é uma herança de valores e objetos compartilhados por um grupo". Para alcançar uma noção ampla sobre a palavra cultura neste trabalho, é necessário entender o conceito antropológico do termo como sendo um conjunto de modos de ser, viver e pensar e falar de uma dada formação social.

Por sua vez, a palavra popular provém da noção de que essa cultura é, acima de tudo, grupal, que resiste à perda de elementos individuais garantindo a sua perpetuação.

A cultura popular vincula-se, tradicionalmente, aos estratos mais pobres, o que não impede o fato de seu aproveitamento pela cultura de massa, vinculada através da televisão, do rádio, do cinema, e pela cultura erudita relacionada aos institutos e universidades. (DINO, 2006, p. 20-21).

Burke (1989) esclarece que, a cultura popular também conhecida como pequena tradição, era transmitida a todos de modo informal, em pequenos espaços como praças ou tavernas. Essa cultura decorre do cotidiano do homem, compreendendo o modo de pensar, agir e falar - por isso difundida essencialmente de forma oral.

Existe também a cultura erudita (ou grande tradição), que, por ser transmitida somente nos Liceus e nas faculdades, torna-se excludente e gera uma relação assimétrica com a pequena tradição.

Dino (2006) ainda reforça que apesar da cultura popular ser um modelo de visão amplamente difundido, ela, geralmente, sofre preconceitos por ser considerada subdesenvolvida e um atraso em relação às tecnologias de comunicação.

Lyotard (1988) explica que atualmente se vive a pós-modernidade, que é marcada pela cibercultura, que abrange as formas de ser e agir nos meios eletrônicos. Por isso, o saber acaba sendo afetado pelas tecnologias da informação, pois os processos de pesquisa foram reestruturados e a transmissão de conhecimento se tornou mais veloz a cada dia.

Desta forma, as mais longínquas partes do mundo podem se interconectar, causando um abalo nas tradições e nas grandes narrativas. Muito da cultura popular se perde porque ela depende de manifestações específicas de um grupo de indivíduos que se enfraquecem com a velocidade com que as informações massificadas se disseminam.

Apesar de alguns autores considerarem que mudança de valores, expressões e comportamentos de determinada cultura, provocam uma fragmentação da cultura popular. Ayala (s/d) considera que, "as práticas culturais populares, na verdade, se modificam, juntamente com o contexto social em que estão inseridas, sem que isso implique necessariamente a sua extinção". Acima de tudo, é considerado que os elementos culturais estão sendo divulgados em outras mídias, sofrendo um processo de recriação contínuo.

Ibid ainda explica que existem pontos de expressão legítimos na cultura popular que são imutáveis e transmitidos através do tempo. Portanto, as histórias da cultura popular continuam as mesmas em sua essência, mesmo que acabem se difundindo através das mídias e ganhando novas interpretações, como, por exemplo, a minissérie "Hoje é dia de Maria" exibida em um canal de TV aberto, baseada em contos populares e recolhida por Sílvio Romero e Luís da Câmara Cascudo. 
A proposta da criação de uma história em quadrinho de terror consiste justamente em identificar as principais expressões dos personagens míticos da cultura popular e promover uma releitura dessas lendas.

A importância do resgate acontece devido às atitudes preconceituosas que tentam denegrir a pequena tradição. Muitos autores da literatura nacional tentam promover uma rica apresentação dos elementos folclóricos em suas obras. Por isso, é importante fazer algumas considerações a respeito do elo entre cultura popular, folclore e o conhecimento tradicional.

A princípio, é necessário definir que folclore compreende o modo de ser, pensar e agir. Lima (2003) menciona que desde 1856 o significado da palavra tem sido o conhecimento das Antiguidades Populares. Fernandes (2003) explica que desde o início dos estudos folclóricos existia uma preocupação em resgatar as manifestações populares para tentar evitar que as formas não fixadas desaparecessem do cotidiano das comunidades.

Entende-se que folclore adquiriu um caráter dinâmico com o passar dos anos. Houve uma desmistificação da palavra - não se trata apenas de estudar os fenômenos passados e curiosos, mas sim de um fenômeno coletivo e dinâmico.

Segundo Brandão (2003) apud Dino (2006), em 1951 notou-se a real valorização dos estudos da cultura popular no Brasil quando ocorreu o I Congresso Brasileiro de Folclore, cujo principal feito foi a elaboração da Carta do Folclore Brasileiro. Definindo o termo conforme o anexo:

1. O I Congresso Brasileiro de Folclore reconhece o estudo do folclore como integrante das ciências antropológicas e culturais, condena o preconceito de só considerar folclórico o fato espiritual e aconselha o estudo da vida popular em toda a sua plenitude, quer no aspecto material, quer no aspecto espiritual.

2. Constituem o fato folclórico as maneiras de pensar, sentir e agir de um povo, preservado pela tradição popular e pela imitação e que não sejam diretamente influenciadas pelos círculos eruditos e instituições que se dedicam à renovação e conservação do patrimônio científico e artístico humano ou à fixação de uma orientação religiosa e filosófica (COMISSÃO PAULISTA DE FOLCLORE, s/d apud DINO, 2006, p. 32).

Considerando que o fato folclórico abrange as maneiras de pensar, sentir e agir de um povo, preservado pela tradição popular, ele se perpetua através das relações interpessoais, principalmente através da oralidade. Portanto, muitos de seus elementos, que são passados de geração para geração, já foram incorporados à obra de escritores renomados, a poesia e prosa erudita brasileira é um exemplo do aproveitamento ou inspiração folclórica.

Quando se fala da relação entre cultura popular e folclore, é necessário ressaltar que a cultura popular está intimamente ligada às definições de povo e de classe. A antropologia sugeria no início que cultura popular era o estudo das manifestações exóticas do folclore, atualmente a definição é mais ampla ao sugerir uma relação com os fenômenos culturais espontâneos.

Dino (2006) afirma que a cultura popular possui uma definição muito ampla, cujas características principais são: o princípio da oralidade, visão cíclica do mundo, culto à memória e o sentimento de pertencer à sociedade da vida. Ela ocorre no âmbito da cultura oral, mas também acaba tendo contato com a cultura escrita e, portanto, acaba promovendo relações da cultura escrita e da cultura oral. 


\section{Estudo De Caso}

Durante o estudo da temática das histórias em quadrinhos como método de divulgação da cultura no TCC, foi feita uma pesquisa quantitativa de 29 de outubro de 2015 a 18 de novembro de 2015, onde 74 pessoas participaram. A coleta de dados se deu por meio da aplicação de um formulário pela internet, com perguntas abertas e fechadas, ressalta-se que esta pesquisa também tinha por objetivo conhecer o público-alvo e não possui rigor estatístico de execução.

Dentre a amostragem de 74 pessoas, 44 eram leitores frequentes de HQs e 30 não eram. Percebeu-se também que, do total de entrevistados, $67,8 \%$ possuem conhecimento sobre os seres que fazem parte da mitologia brasileira, sendo que os mais mencionados foram Matinta-Pereira, Saci, Boto, Curupira e lara.

Quando perguntados, os participantes disseram que preferem as lendas brasileiras às europeias e $87,8 \%$ disseram que comprariam uma história em quadrinhos de terror inspirada nas lendas populares brasileiras. Esses resultados demostram a existência de um mercado consumidor interessado em histórias em quadrinhos com uma temática que ainda não foi abordada.

Os participantes da pesquisa afirmaram que tem interesse pelas lendas populares brasileiras, mas, mesmo assim, essas lendas estão sendo esquecidas. O que se pressupõe que tal fato ocorra devido à escassez de material relacionado ao tema ou à falta de divulgação do material existente. Como resultado final, foi criada uma história em quadrinhos de terror da Matinta-Pereira com o objetivo propagação da lenda.

Utilizou-se o design editorial, design de livros e a semiótica para tornar a história em quadrinhos muito mais atrativa visualmente para os leitores, tornando a interface do produto muito mais agradável ao usuário. Segundo Noman (2004) apud Cybis et al (2010), afirma que a formação e o armazenamento da memória são influenciados pelas emoções. A interação do usuário com um produto pode produzir emoções boas ou ruins dependendo da interface do produto. $O$ Neurocientista Damásio (s/d) afirma que as emoções modulam como a memória é armazenada no cérebro e que tomadas de decisão são completamente influenciadas pela memória.

Uma experiência de frustração com algum produto pode fazer o usuário não querer mais utilizar aquela interface - uma vez que as memórias mais lembradas são as negativas. De acordo com Sutclife (2005), uma boa usabilidade é lembrada de modo geral, mas a usabilidade ruim é lembrada detalhadamente.

Unger (2009), explica que as emoções também são importantes para os projetistas, porque assim será feita a conexão com o usuário e será criada uma estrutura lógica na qual o usuário se conectará com o produto.

\footnotetext{
Alcançar esse equilíbrio requer um senso de empatia maior: a habilidade de auto imersão nos dois mundos dos usuários de produtos potenciais para compreender suas necessidades e motivações. Os projetistas da experiência do usuário realizam a pesquisa para alcançar sua compreensão e criar tais ferramentas como personas, para ajudar o restante da equipe de projeto a focar em seus esforços (UNGER, 2009, p. 7).
}

Em relação aos quadrinhos, pode-se transpor esse conceito e traçar uma analogia. Quando uma pessoa lê uma história em quadrinhos pela primeira vez, a experiência que ela terá é muito 
importante, pois definirá se ela irá procurar mais sobre aquele conteúdo ou se aquilo é irrelevante para ela.

Com o intuito de dar prosseguimento ao estudo e validar a temática abordada, utilizou-se a história em quadrinhos da Matinta-Pereira para realizar um estudo de caso com 16 alunos entre 11 e 14 anos, de ambos os sexos, de uma turma de Fudamental II da escola pública estadual Erc E F Centro Social Auxilium, localizada no bairro da Pedreira, Belém-PA.

A escolha da escola pública foi feita levando em consideração a escassez de acesso a materiais culturais que, geralmente, os alunos de escolas públicas têm. Porém, a escolha da escola Erc E F Centro Social Auxilium foi feita de forma aleatória. A escolha da turma foi feita baseada na faixa etária necessária para o entendimento das perguntas do questionário aplicado.

A turma foi dividida em 2 grupos. Para 8 alunos foi entregue a história em quadrinhos de terror da Matinta-Pereira e aos outros 8 foi entregue um texto escrito contendo exatamente 0 mesmo enredo da história. Após o término da leitura, foi entregue um questionário quali-quanti com perguntas relacionadas ao conteúdo cultural abordado para descobrir qual dos dois grupos absorveu mais informações.

\subsection{Análise De Resultados}

Com o objetivo de criar uma análise estatística do resultado, foram atribuídos pontos às perguntas, resultando em uma pontuação máxima de 5 pontos por questionário. No total, os alunos que leram o texto fizeram 26 pontos, enquanto que os que leram a história em quadrinhos fizeram 29 pontos.

Uma das perguntas do questionário questionava o que o leitor considerava mais interessante na história; ela ser de terror ou ela ser sobre o folclore brasileiro. Dos que leram o texto, 4 responderam que acharam mais interessante o fato da história ser de terror, ao passo que, dos que leram que a $\mathrm{HQ}, 7$ disseram que acharam mais interessante o fato dela ser sobre o folclore brasileiro. Com este resultado, é possível interpretar que a criação dos cenários e dos personagens, criada por meio da metodologia de painéis de inspiração de Baxter, juntamente com a diagramação dos quadros e estruturamento físico da $\mathrm{HQ}$, feita através dos conceitos de design editorial, tornou o conteúdo do folclore brasileiro mais atrativo para o leitor. Despertando o interesse do leitor pelo folclore brasileiro de melhor forma do que o através do texto.

As perguntas do questionário eram de reposta fechada e única, com exceção de uma pergunta de resposta aberta, onde as crianças não tinham a opção de escolher uma resposta aleatoriamente e acertá-la por coincidência. Nesta pergunta, 3 das crianças que leram o texto responderam errado e 1 deixou a resposta em branco. Das que leram a $\mathrm{HQ}$, apenas 1 errou a pergunta e 1 não respondeu.

Observou-se que, dos 8 alunos que leram o texto, 4 tentaram copiar as respostas do questionário de outros alunos por não se lembrarem de alguns fatos do texto, o mesmo tipo de comportamento não foi observado em nenhum dos 8 que leram a HQ. Mostrando que a conexão do usuário com o produto foi mais relevante no caso da história em quadrinhos e, por isso, a memória visual foi superior à memória semântica.

Constatou-se que todos os alunos que leram a $\mathrm{HQ}$ levaram mais tempo lendo, pois eles analisavam não somente o roteiro, mas também o conteúdo visual da história em quadrinhos; personagens, cenários, estrutura das falas e até mesmo a textura do papel impresso. Revelando que 
houve maior interesse pelo conteúdo do material como um todo pelas crianças que leram a história em quadrinhos.

\section{Conclusão}

Levando em consideração a pontuação final dos grupos e que na pergunta de resposta aberta a média dos alunos que leram a $\mathrm{HQ}$ e acertaram é maior do que a dos que leram o texto, concluiu-se que realmente existe a possibilidade de aprendizado da cultura popular brasileira através das histórias em quadrinhos.

Também se observou que não existe uma correlação entre gêneros e a absorção de conteúdo através das histórias em quadrinhos. Dentre os 8 alunos, ambos os sexos acertaram uma quantidade de respostas relativamente similar, apesar de ser comum relacionar quadrinhos ao gosto masculino. Se o design editorial se encarregar de produzir um conteúdo sem direcionamentos e que seja atrativo para ambos os sexos, o alcance do produto será muito maior.

A utilização do design gráfico, design editorial, de livros e o uso da semiótica como ferramenta no processo de construção da história em quadrinhos tornou o produto muito mais atrativo para o leitor, criando um armazenamento de memória gerado através da conexão visual do usuário com o produto muito melhor do que a memória gerada pela conexão semântica.

A análise empírica do estudo de caso revelou que materiais de caráter imagético são mais atrativos entre jovens, tendo em vista que do grupo que leu o texto, 3 alunos pediram para ler a $\mathrm{HQ}$ também, mesmo sabendo que esta possuía a mesma história. Demonstrando que, quando há um material de divulgação atrativo sobre a cultura popular brasileira, existe um interesse e uma curiosidade sobre o conteúdo da mesma.

A pesquisa conclui que a história em quadrinhos comunicou o que precisava e que, por isso, cumpriu com o seu objetivo de criar nos leitores memórias das lendas populares brasileiras. Portanto, este é um método eficaz de divulgação da cultura. E que após o primeiro contato com uma história em quadrinhos sobre o folclore brasileiro, as crianças que fizeram parte da pesquisa mostraram interesse em conhecer mais da cultura popular brasileira. 


\section{Referências}

BURKE, P. Cultura popular na Idade Moderna. São Paulo: Companhia das Letras, 1989.

CYBIS, Walter et al. Ergonomia e usabilidade: Conhecimentos, Métodos e Aplicações. Novatec, 2007

DINO, Dafne. Num ninho de mafagafos: literatura infantil de inspiração folclórica e a formação do leitor literário. Passo Fundo, 2006.

FERNANDES, F. O folclore em questão. São Paulo: Martins Fontes, 2003.

FUENTES, Rodolfo. A prática do design gráfico: uma metodologia criativa; tradução Osvaldo Rosiano. São Paulo: Edição Rosari, 2006.

LIMA, R. T. Abecê do folclore. São Paulo: Martins Fontes, 2003.

LYOTARD, Jean-françois. O Pós-Moderno. Rio de Janeiro: José Olympo, 1988.

MCLOUD, Scott. Desenhando quadrinhos. São Paulo, M. Books do Brasil, Ltda, 2008.

PANIZZA, Janaina. Metodologia e processo criativo em projetos de comunicação visual. São Paulo, 2004.

SOUSANIS, Nick. Unflattening. Cambrigde. Harvard University Press. 2015.

UNGER, Russ et al (2009). O guia para projetar UX; tradução Elda Oliveira. Rio de Janeiro: Alta Books Editora, 2009. 